\title{
Unmanned aerial vehicle canopy reflectance data detects potassium deficiency and green peach aphid susceptibility in canola
}

\author{
Dustin Severtson $^{1,2} \cdot$ Nik Callow $^{3} \cdot$ Ken Flower $^{4}$. \\ Andreas Neuhaus ${ }^{5} \cdot$ Matt Olejnik $^{6} \cdot$ Christian Nansen $^{7}$
}

Published online: 15 March 2016

(C) The Author(s) 2016. This article is published with open access at Springerlink.com

\begin{abstract}
There is growing evidence that potassium deficiency in crop plants increases their susceptibility to herbivorous arthropods. The ability to remotely detect potassium deficiency in plants would be advantageous in targeting arthropod sampling and spatially optimizing potassium fertilizer to reduce yield loss due to the arthropod infestations. Four potassium fertilizer regimes were established in field plots of canola, with soil and plant nutrient concentrations tested on three occasions: 69 (seedling), 96 (stem elongation), and 113 (early flowering) days after sowing (DAS). On these dates, unmanned aerial vehicle (UAV) multi-spectral images of each plot were acquired at 15 and $120 \mathrm{~m}$ above ground achieving spatial (pixel) resolutions of 8.1 and $65 \mathrm{~mm}$, respectively. At 69 and 96 DAS, field plants were transported to a laboratory with controlled lighting and imaged with a 240-band (390-890 nm) hyperspectral camera. At 113 DAS, all plots had become naturally infested with green peach aphids (Hemiptera: Aphididae), and intensive aphid counts were conducted. Potassium deficiency caused significant: (1) increase in concentrations of nitrogen in youngest mature leaves, (2) increase in green peach aphid density, (3) decrease in vegetation cover, (4) decrease in normalized difference vegetation indices (NDVI) and decrease in canola seed yield. UAV imagery with $65 \mathrm{~mm}$ spatial resolution showed higher
\end{abstract}

Dustin Severtson

dustin.severtson@ research.uwa.edu.au

1 School of Animal Biology and The UWA Institute of Agriculture, The University of Western Australia, 35 Stirling Highway, Crawley, Perth, WA 6009, Australia

2 Department of Agriculture and Food Western Australia, 3 Baron-Hay Court, South Perth, WA 6151, Australia

3 Environmental Dynamics and Ecohydrology, School of Earth and Environment, The University of Western Australia, 35 Stirling Highway, Crawley, WA 6009, Australia

4 School of Plant Biology and The UWA Institute of Agriculture, The University of Western Australia, 35 Stirling Highway, Crawley, WA 6009, Australia

5 CSBP Limited, Kwinana Beach Road, Kwinana Beach, WA 6167, Australia

6 Sensorem, 1/34 Kings Park Road, West Perth, WA 6932, Australia

7 Department of Entomology and Nematology, UC Davis Briggs Hall, Davis, CA, USA 
classification accuracy (72-100\%) than airborne imagery with $8 \mathrm{~mm}$ resolution (69-94\%), and bench top hyperspectral imagery acquired from field plants in laboratory conditions (78-88\%). When non-leaf pixels were removed from the UAV data, classification accuracies increased for $8 \mathrm{~mm}$ and $65 \mathrm{~mm}$ resolution images acquired 96 and 113 DAS. The study supports findings that UAV-acquired imagery has potential to identify regions containing nutrient deficiency and likely increased arthropod performance.

Keywords Potassium deficiency $\cdot$ Arthropod performance $\cdot$ Remote sensing - Green peach aphid · Canopy reflectance

\section{Introduction}

Arable soils in many broad-acre agricultural areas have become deficient in potassium (K) as a result of $\mathrm{K}$ removal in grain and hay (Brennan et al. 2013; Zörb et al. 2014). Plants deficient in K exhibit limited growth, metabolism and stress defence (Wang et al. 2013) which leads to lower yield and quality of grain and hay. Due to these factors, there is growing scientific support that K-deficiency in plants allows for increased performance of herbivorous arthropods (Wang et al. 2013; West and Nansen 2014) which further stresses plants and diminishes yields and quality. Information regarding the effects of K-deficiency on the performance of economically important arthropod pests would benefit agricultural production specialists by emphasizing the importance of $\mathrm{K}$ nutrition, not just for optimal growth but also for plant defence against key arthropod pests and diseases.

It is laborious, time consuming and costly to sample and test soils or plant material over large areas for concentrations of $\mathrm{K}$ in order to adequately map concentrations. The spatial heterogeneity of $\mathrm{K}$ at various scales throughout a field limits the ability to interpolate point-sourced soil or plant nutrient concentration data (Cook and Bramley 2000). Accurate maps of $\mathrm{K}$ deficiency are required for variable-rate applications of fertilizers, or to understand areas of more likely arthropod infestation. There is a need to identify means other than direct soil and plant tissue sampling, in order to identify where nutrient deficiencies impose serious constraint to crop performance, and to investigate the links between $\mathrm{K}$ deficiency and arthropod infestation.

Image-based canopy reflectance data are acquired using cameras which record values for multi-spectral (2-10) or hyperspectral $(>10)$ bands of radiation in the visible and nearinfrared spectra (Whelan and Taylor 2013). The use of UAVs and lightweight imaging cameras have recently given agricultural industries the ability to cheaply and rapidly collect canopy reflectance data from crops (Watts et al. 2012; Colomina and Molina 2014). UAV-based imaging also has advantages of: flexibility in choice of camera height above subject, flexibility in spectral resolution via choice of sensors, and equipment is small, fast and easy to transport and allows for timely deployment at specific crop life stages.

One of the greatest benefits of using a UAV over satellite as a means of obtaining reflectance data from crops is that much higher spatial resolutions, customisable spectral resolution and more flexible temporal collection allows for high quality and more specific information to be obtained about the target plants (Zhang and Kovacs 2012). Image-based plant canopy-sensing has the advantage of detecting the real-time performance of plants with high spatial and temporal flexibility. Also, unexplained variability in crop performance can be detected during the growing season and field regions containing plants which 
display sub-optimal plant growth or abnormal reflectance may be targeted for on-ground inspection and validation. This is important because many biotic or abiotic stresses often exhibit similar plant responses such as altered leaf area index (LAI), stomatal closure, and inhibition of photosynthesis; this makes individual stresses (e.g. K-deficiency) difficult to differentiate in the field (Jones and Vaughan 2010).

The most common use of canopy reflectance data in broad-scale agriculture is to assess the amount and quality of crop growth which is used in decision making and yield prediction (Whelan and Taylor 2013). Most studies classifying abiotic or biotic stress using canopy reflectance data have focused on the use of vegetation indices (Jones and Vaughan 2010, Prabhakar et al. 2012). The resultant value for each pixel is either mapped to visualize the heterogeneity of index values or mean index values calculated per unit area. Lee et al. (2010) questioned whether the spectral signatures calculated using all pixels (e.g. vegetation indices) are "purely pest related, or a mixture in which radiation from soil and senescent leaves increases with infestation intensity." Therefore, analysis of both leaf pixels (i.e. filtering out the background) and all image pixels may be useful in combination where it is unknown whether the particular stress in question (e.g. K-deficiency) is causing either reduced LAI, altered reflectance of leaves, or both. Remote sensing of plant nutrients has mostly been applied to nitrogen (Muñoz-Huerta et al. 2013; Mahajan et al. 2014), with only a limited number that have attempted to classify potassium deficiency, including wheat (Pimstein et al. 2011; Mahajan et al. 2014) and rice (Chen et al. 2014). Canopy reflectance data has also been used to detect biotic stresses including arthropod pests (Prabhakar et al. 2012), but no studies are known to have assessed relationships between UAV-based remote sensing of potassium deficiency in plants and the performance of herbivorous arthropods.

It was hypothesized that K-deficient canola plants could be differentiated from K-sufficient plants, using canopy reflectance data, which was acquired using a UAV (multispectral) and under experimental laboratory conditions (hyperspectral). A second hypothesis was that K-deficient canola plots would contain significantly more green peach aphids (GPA; Myzus persicae Sulzer) than K-sufficient canola plants, as K-deficiency is known to increase crop susceptibility to arthropod pests.

\section{Materials and methods}

\section{Experimental plots}

Experimental plots $(2 \mathrm{~m} \times 20 \mathrm{~m})$ were established on a Marri gravelly sandy loam soil type in a field near Williams, Western Australia $\left(-33.037116^{\circ} \mathrm{S}, 116.823755^{\circ} \mathrm{E}\right) . \mathrm{K}$ was applied in the form of muriate of potash (MOP) (CSBP Limited, Kwinana, Perth, Australia; $\%$ w/w $50 \mathrm{~K}, 46 \mathrm{Cl}$ ). There were a total of 12 plots established in 2012 that consisted of four $\mathrm{K}$ treatments (i.e. applications) with three replicates in a randomized block design: nil MOP (per year 2012-2014) designated as low K, $50 \mathrm{~kg} \mathrm{ha}^{-1}$ MOP (per year 2012-2014) as medium $\mathrm{K}, 100 \mathrm{~kg} \mathrm{ha}^{-1} \mathrm{MOP}$ (per year 2012-2014) as high $\mathrm{K}$ and $400 \mathrm{~kg} \mathrm{ha}^{-1} \mathrm{MOP}$ (2012 only) as residual K. The last treatment was considered as "residual K" because all MOP was applied in 2012 and no MOP applied during 2013 or 2014. Oats were sown in 2012 and 2013. Canola cultivar Crusher TT was sown, on 22 May 2014, at a rate of $3.5 \mathrm{~kg} \mathrm{ha}^{-1}$ with adequate soil moisture for seed germination. Weeds were controlled via herbicide sprays on 19 May ( $720 \mathrm{~g}$ a.i. (active ingredient) $\mathrm{ha}^{-1}$ glyphosate as 
isopropylamine salt; $1000 \mathrm{~g}$ a.i. $\mathrm{ha}^{-1}$ atrazine) and $21 \mathrm{July}$ (1000 $\mathrm{g}$ a.i. ha ${ }^{-1}$ atrazine; $144 \mathrm{~g}$ a.i. ha ${ }^{-1}$ clethodim). Insecticide sprays were applied on 19 May (150 g a.i. ha ${ }^{-1}$ chlorpyrifos) and 22 May (100 g a.i. ha ${ }^{-1}$ bifenthrin) prior to canola germination. Basal fertilizer without $\mathrm{K}: 103 \mathrm{~kg} \mathrm{ha}^{-1}$ Agflow Extra ${ }^{\circledR}$ (CSBP Limited, Kwinana, Australia; \%w/w 12.7 N, 17.7 P, 5.6 S, 0.1 Cu, 0.2 Zn, 0.01 Mn) and $801 \mathrm{ha}^{-1}$ liquid urea ammonium nitrate (CSBP Limited, Kwinana, Australia; Flexi-N ${ }^{\circledR}$; \%w/w $32 \mathrm{~N}$ comprised of 8 $\mathrm{NO}_{3}, 8 \mathrm{NH}_{4}, 16$ urea) were banded into the soil at sowing for all plots in 2014. NS41 fertilizer (CSBP Limited, Kwinana, Australia; \%w/w 35 N, 0.6 P, 8.9 S) was spread on all plots at $200 \mathrm{~kg} \mathrm{ha}^{-1}$ on 30 June.

\section{Soil and plant nutrients}

Soil and plant tissue nutrient analyses were undertaken by CSBP Soil and Plant Analysis Laboratory (Bibra Lake, Western Australia) for samples taken 69, 96 and 113 days after sowing (DAS); these were 29 July, 25 August and 11 September, and decimal growth stages were 1.04-1.08 (4-8 leaf seedling), 2.1-3.5 (stem elongation to budding) and 3.5-4.5 (budding to early flowering) (Edwards and Hertel 2011). On these dates, three soil cores of $35 \mathrm{~mm}$ diameter and $0.30 \mathrm{~m}$ depth were taken and combined to form one bulk soil sample per plot. Soil samples were tested for: Colwell P, Colwell K, Sulphur ( $\mathrm{KCl} \mathrm{40),}$ organic carbon (Walkley-Black), $\mathrm{NO}_{3}, \mathrm{NH}_{4}$, electrical conductivity (1:5 soil/water), $\mathrm{pH}$ (water) and $\mathrm{pH}\left(0.01 \mathrm{M} \mathrm{CaCl}_{2}\right)$ using methods described by Rayment and Lyons (2011). Plant tissue samples consisted of 20 randomly selected whole shoot canola plants at 69 DAS (because plants were 5-6 leaf growth stage) and 20 randomly selected "youngest mature leaves" per plot 96 and 113 DAS. Plant tissue samples were tested for: N, P, K, S, $\mathrm{Cu}, \mathrm{Zn}, \mathrm{Mn}, \mathrm{Ca}, \mathrm{Mg}, \mathrm{Na}, \mathrm{Fe}, \mathrm{B}, \mathrm{NO}_{3}$ and $\mathrm{Cl}$ using methods described by Loss (2012).

\section{Multi-spectral image acquisition}

Images were acquired 69, 96 and 113 DAS using a 6-channel Tetracam ${ }^{\circledR}$ miniature multicamera array (MCA) (Mini-MCA6; Tetracam Inc., Chatsworth, CA, USA) mounted underneath an 8-rotor remote-controlled UAV (Cinestar-8 MK Heavy Lift, Freefly Systems, Redmond, WA, USA). The UAV was controlled by operators from Civil Aviation Safety Authority (CASA)-certified UAV operator "Sensorem" and flown at both 15 and $120 \mathrm{~m}$ above ground.

Images (1.3 megapixel; $1280 \times 1024$ pixels) were captured in each of the MCA's six cameras as 10 bit RAW files (totalling 7.8 megapixels). The Mini-MCA6 specifications are: Field of view $=38.26^{\circ}(\mathrm{x})$ by $30.97^{\circ}(\mathrm{y})$; image spatial resolution $=1280 \times 1024$ pixels; focal length $=9.6 \mathrm{~mm}$; sensor dimensions $=6.66 \mathrm{~mm}$ (width) $\times 5.32$ (height) $\mathrm{mm}$. The image footprints for 15 and $120 \mathrm{~m}$ heights were $10.4 \mathrm{~m}(\mathrm{x}) \times 8.3 \mathrm{~m}(\mathrm{y})$ and $83.2 \mathrm{~m} \times 66.5 \mathrm{~m}$, respectively. This equated to a ground pixel resolution of $8.1 \mathrm{~mm} \times$ $8.1 \mathrm{~mm}$ and $65 \mathrm{~mm} \times 65 \mathrm{~mm}$, respectively, for 15 and $120 \mathrm{~m}$ heights. The $15 \mathrm{~m}$ height was chosen because it was the lowest height the UAV could be flown without significant 'buffeting' of the canola canopy from rotor "downwash". The height of $120 \mathrm{~m}$ represents the $122 \mathrm{~m}$ vertical ceiling imposed by CASA for normal UAV operations. Images were acquired at $120 \mathrm{~m}$ above ground to compare classification accuracies at the two heights. All images were acquired between $11 \mathrm{am}$ and $1 \mathrm{pm}$. An auto-stabilizing gimbal ensured all images were acquired from a vertical position, even when the UAV was not stable. White radiometric calibration was done by placing white Teflon boards (K-Mac Plastics, MI, USA) in each plot and comparing its reflectance to the proportional reflectance within each 
plot to determine the relative reflectance. Images acquired at $15 \mathrm{~m}$ contained approximately one third of each $2 \mathrm{~m} \times 20 \mathrm{~m}$ plot; the same plot sections were imaged per imaging date. Images acquired at $120 \mathrm{~m}$ contained plots in their entirety. In order to avoid technical issues regarding vignetting (i.e. brightness reductions at image peripherals) (Kelcey and Lucieer 2012), data were extracted from central portions of images and across Teflon boards.

\section{Multi-spectral data processing}

The software PixelWrench $2^{\circledR}$ (Tetracam Inc., Chatsworth, CA, USA), which is supplied with the MCA, was used to transfer the 10-bit RAW images from the camera to a computer. The six images per image-capture event were registered with each other using the MCA Index Tool within PixelWrench2. First, the MCA alignment file was loaded, which contains the manufacturer's camera settings to correct for $\mathrm{x}, \mathrm{y}$, rotation and scaling and registers each slave camera image to the master camera image prior to writing them to TIF. The images were aligned with the field of view 'distance to object' settings (i.e. 15 or $120 \mathrm{~m}$ ). This band-to-band registration method was more accurate than the option of manually producing an alignment file. The images were exported as single-page TIF files with 10-bit colour depth. A Python (Python Software Foundation; available at http://www. python.org) script was produced to convert the six registered image files into one 10-bit BSQ file. Data for each combination of plot $(\mathrm{N}=12)$, height $(\mathrm{N}=2)$ and imaging date $(\mathrm{N}=3$ ) were extracted using the spectral analysis software, Spectronon Pro (Resonon Inc., Bozeman, MT, USA).

As in similar studies (Nansen et al. 2013a), radiometric filters were applied to remove background 'non-leaf' pixels (i.e. soil, stubble, shadow, flowers). Bands $3(680 \mathrm{~nm})$ and 5 $(800 \mathrm{~nm})$ were selected because they are frequently used in the calculation of the normalized difference vegetation index (NDVI) (Rouse et al. 1974) which is robust in discriminating vegetation from non-vegetation in a variety of conditions (Pettorelli 2013). Firstly, for each combination of imaging date $(\mathrm{N}=3)$ and camera height $(\mathrm{N}=2)$, five subsets of $>100$ pixels were extracted of 'leaf' pixels and 'non-leaf' pixels (including soil, stubble and shadow). An additional category of background was used to remove flower pixels at 113 DAS. Graphical boxplots were created for each subset at bands 3 and 5, for each subset, and the reflectance values which showed greatest separation between leaf and background categories for all three imaging dates were chosen for each image resolution (i.e. 15 and $120 \mathrm{~m}$ ). Thus, for $15 \mathrm{~m}$ images, pixels were only included if the reflectance values for bands 3 (B3) and 5 (B5) met the following criterion: B3 $<0.40$ and B5 $>0.70$ (Fig. 1). The criterion for pixels retained for $120 \mathrm{~m}$ images was: $\mathrm{B} 3<0.30$ and $\mathrm{B} 5>0.45$ (Fig. 2). The ability of the radiometric filters in excluding background pixels was visualized in ArcMap (ESRI 2014) using the Raster Calculator tool by implementing the above conditional expressions and visualizing the 'filtered' raster over the original image (see Figs. 1, 2). The same filters could not be applied to both spatial resolutions (image heights) because there was much more overlap between leaf and background reflectance profiles for $120 \mathrm{~m}$ images. Therefore, the filter for $120 \mathrm{~m}$ images was created by mapping the initial filter used for $15 \mathrm{~m}$ images and decreasing the B3 and B5 thresholds until at least 100 leaf pixels could be extracted from each plot. It was evident then that background pixels were effectively excluded in $15 \mathrm{~m}$ (8.1 mm pixel) images (Fig. 1), but pure leaf pixels were either difficult or unable to be selected at $65 \mathrm{~mm}$ pixel size in $120 \mathrm{~m}$ images (Fig. 2).

Plot regions within images were divided into three sub-regions to achieve three relative reflectance values for each combination of plot and imaging date. Average reflectance 


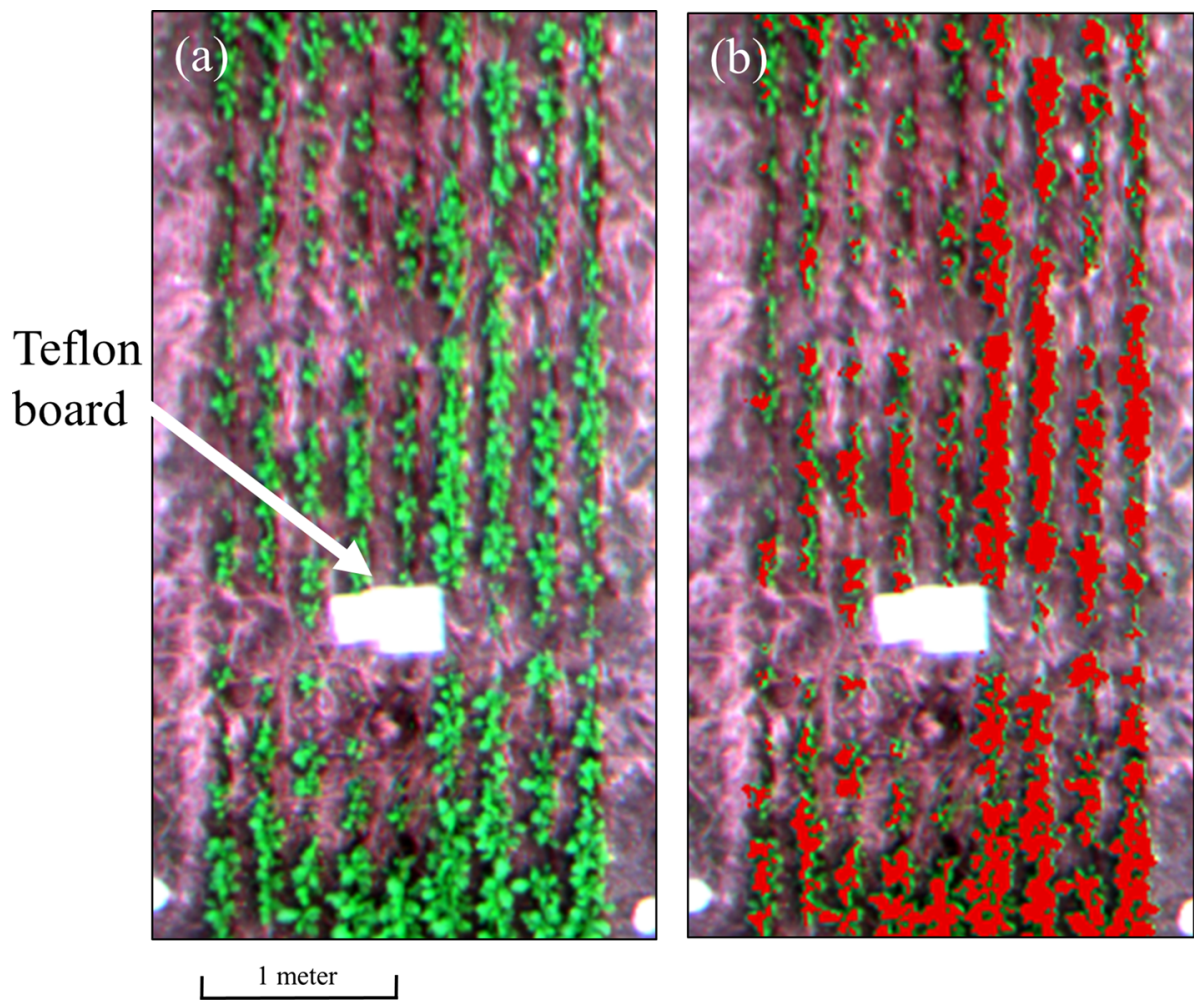

Fig. 1 True color (bands 490, 560, 680) images of plot taken at 69 DAS at $15 \mathrm{~m}$ above ground showing: canola plants (a) and pixels in red selected as leaf pixels (b) using radiometric filter to remove non-leaf pixels. White squares are Teflon boards used in calibration of canopy reflectance

profiles were calculated before (all pixels) and after (leaf pixels) radiometric filters were applied. Using average reflectance profiles eliminated issues regarding individual pixel comparison and poor pixel registration.

\section{Hyperspectral image acquisition}

On 69, 96 and 113 DAS, three canola plants at the same growth stage (per date) were transplanted along with the respective plot soil into 5 litre plastic pots for subsequent hyperspectral imaging. Plants were acclimatized in a glasshouse for 7 days at which point all plants appeared turgid and healthy. A 'push-broom' hyperspectral camera (PIKA II, Resonon Inc., Bozeman, MT, USA) mounted $0.40 \mathrm{~m}$ above the canola plants, acquired images of each plant from above, as in Nansen et al. (2013b). The technical specifications of the camera were: interface, Firewire (IEEE 1394b); output, digital (12-bit); 240 bands from 392 to $889 \mathrm{~nm}$ (spectral resolution $=2.1 \mathrm{~nm}$ ) (spectral) by 640 pixels (spatial); angular field of view of $7^{\circ}$. The objective lens was optimized for the near-infrared and visible near-infrared spectra with $35 \mathrm{~mm}$ focal length (maximum aperture of F1.4). Hyperspectral images were collected under artificial lighting from $15 \mathrm{~W}$, two $12 \mathrm{~V}$ LED light bulbs mounted on either side of the lens in an $18-22{ }^{\circ} \mathrm{C}$ room with $30-40 \%$ humidity. Reflectance data were acquired with the spatial resolution of 49 ( 7 by 7 ) pixels 

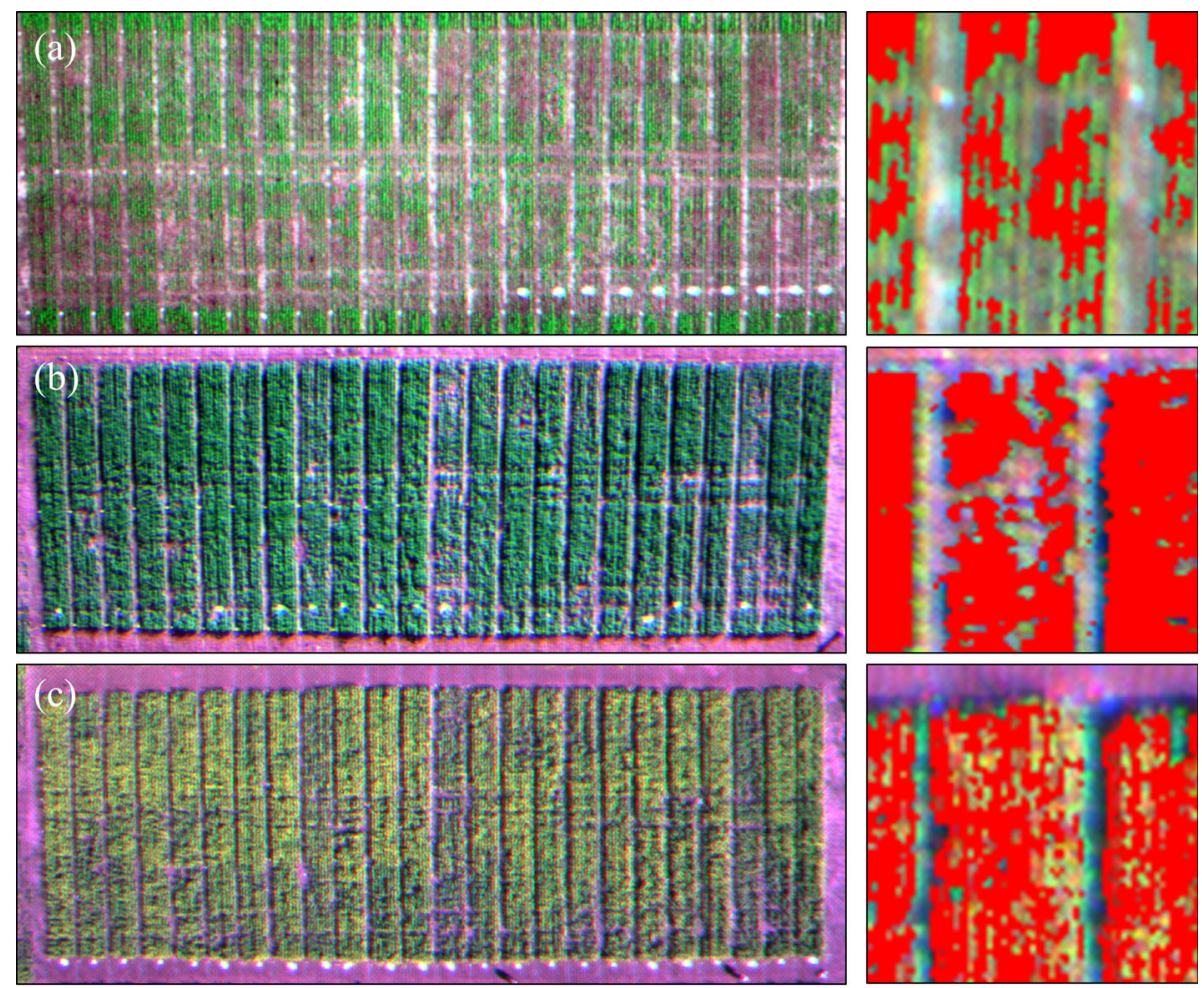

10 meters

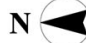

Fig. 2 True color (bands 490, 560, 680) images acquired on 69 DAS (a), 96 DAS (b), and 113 DAS (c) at $120 \mathrm{~m}$ above ground. Images to the right show pixels in red selected as leaf pixels using radiometric filter; 12 of the 24 plots were used in this study as they represent the four K-fertilizer regimes. White squares are Teflon boards used in calibration of canopy reflectance

per $\mathrm{mm}^{2}$. White calibration was done with white Teflon (K-Mac Plastics, MI, USA) and its reflectance was compared to the proportional reflectance to determine the "relative reflectance". Further to white calibration, coloured plastic cards (green, yellow and red) were imaged before and after each imaging session, and less than $2 \%$ variance occurred in average reflectance profiles of each spectral band.

\section{Hyperspectral data processing}

All hyperspectral images consisted of 100 frames (64 000 pixels) with relative reflectance ranging between 0 and 1 . Each image was spatially averaged (binned) in a $10 \times 10$ grid to 640 pixels, as this was shown to increase classification accuracy (Nansen et al. 2013a). Spectra were also binned by 3 (from 2.1 to $6.3 \mathrm{~nm}$ ). The first and last 10 spectral bands were omitted because they are typically associated with proportionally higher levels of stochasticity/noise, which resulted in 73 spectral bands from 411 to $871 \mathrm{~nm}$ being included in the analysis. The spectral binning was conducted to increase classification accuracy (Nansen et al. 2013a) and to reduce the risk of model over-fitting (Defernez and Kemsley 
1997). As with the multi-spectral data processing, a radiometric filter was applied to the extracted image data to include only leaf pixels.

\section{Green peach aphid (GPA) infestation}

There was no GPA infestation prior to 96 DAS. However, all plots became naturally infested by 113 DAS. Consequently, plants were not taken for hyperspectral imaging in the lab. Intensive GPA counts were done wherein five randomly-selected points were chosen per plot and 10 whole plants were inspected for total GPA per plant along the crop row at each point (50 plants per plot).

\section{Data analyses}

Statistical analyses were conducted using Genstat for Windows v.15 (VSN International Ltd., Hemel Hemstead, UK). Stepwise discriminant analysis with forward selection was performed on multi-spectral (with and without background removal) and hyperspectral data to determine the accuracy of classifying K-deficient canola plants in relation to K-sufficient canola plants. Discriminant analysis has successfully been employed to classify agriculturally important traits of soil (Ge et al. 2011) and plant canopy reflectance data (Nansen et al. 2010, 2013a). Optimal bands were selected in the model based on Wilk's Lambda statistical criteria. Five-fold cross validation was conducted to calculate classification accuracy and avoid model over-fitting (Defernez and Kemsley 1997). This validation randomly removes $20 \%$ of the data for validation, per simulation; 100 simulations were run per analysis. Analysis of variance was performed to assess differences in soil and plant nutrient concentrations, canola seed yield and green peach aphid counts between $\mathrm{K}$ treatments. Regression analyses were performed on LAI against NDVI and K against $\mathrm{N}$ in plant tissue.

\section{Results}

\section{Leaf nutrient and crop yield data}

Of the four $\mathrm{K}$ fertilizer regimes employed in the field study, plant tissue analysis found that only canola plants in the low K treatment (i.e. nil MOP applied 2012-2014) showed a deficiency in $\mathrm{K}$, a result consistent with previous research (Brennan and Bolland 2006, 2007). Average soil $\mathrm{K}$ in the low $\mathrm{K}$ treatment $69 \mathrm{DAS}$ was less than $40 \mathrm{mg} \mathrm{kg}^{-1}$ while average medium, residual and high $\mathrm{K}$ treatments tested above $57 \mathrm{mg} \mathrm{kg}^{-1}$ (Fig. 3a). These soil $\mathrm{K}$ concentrations resulted in two divergent classes of plant tissue $\mathrm{K}$ concentrations which are here considered K-deficient (one treatment) and K-sufficient (three treatments). This is evidenced by averages of less than $2 \% \mathrm{~K}$ in plant tissue from the low $\mathrm{K}$ treatment and greater than $3.5 \% \mathrm{~K}$ in plant tissue in the three other treatments at $69 \mathrm{DAS}$; these differences were significant $(\mathrm{F}=74.71 ; \mathrm{df}=3,11 ; \mathrm{P}<0.01)$ (Fig. 3b). Designating the medium $\mathrm{K}$, residual $\mathrm{K}$ and high $\mathrm{K}$ treatments into one class is further supported by the yield data wherein no significant differences were seen between these treatments yet all were significantly higher than the low $\mathrm{K}$ treatment $(\mathrm{F}=52.92 ; \mathrm{df}=3,11 ; \mathrm{P}<0.01)$ (Fig. 3e). This differentiation among low $\mathrm{K}$ and the three other treatments was consistent for plant tissue $\mathrm{K}$ analysis throughout the trial (based on data at 96 and $113 \mathrm{DAS}$ ). 

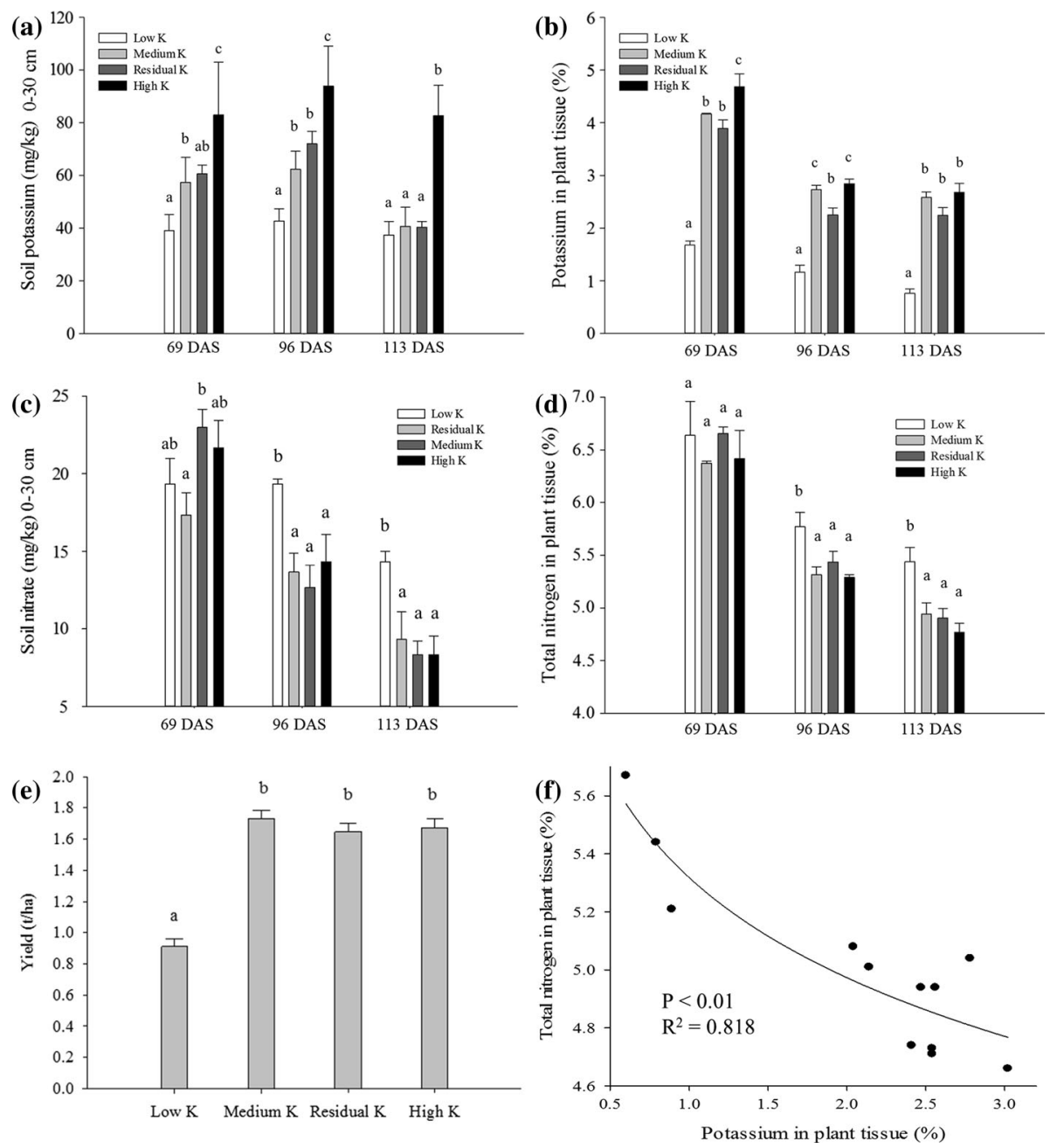

Fig. 3 Soil K (mg/kg) (a), plant tissue K (\%) (b), soil nitrate $(\mathrm{mg} / \mathrm{kg})(\mathbf{c})$, and total plant tissue nitrogen (\%) (d) for low, medium, residual and high $\mathrm{K}$ fertilizer regimes at 69, 96, and $113 \mathrm{DAS}$; harvested canola seed yield ( $\mathrm{t} / \mathrm{ha})$ for the four fertilizer regimes $(\mathbf{e})$. Note that alike letters indicates like means $(\mathrm{P}<0.05)$ and error bars indicate standard error of mean. Concentrations of $\mathrm{K}$ in relation to total $\mathrm{N}$ in youngest mature leaves per plot at the time of GPA infestation 113 DAS (f)

With regard to the other nutrients tested in soil and plant samples, there were no significant differences between the four treatments with the exception of soil nitrate ("soil N") and total nitrogen in plant tissue ("plant N"). Figure 3 shows that although soil N (Fig. 3c) and plant N (Fig. 3d) initially exhibited sufficient concentrations at seedling growth stages (69 DAS), concentrations of both factors decreased significantly at 96 DAS and decreased further at 113 DAS. Significantly higher concentrations of soil N and plant $\mathrm{N}$ were evident in the low K treatment than other treatments at 96 and 113 DAS, while no differences were seen between medium, residual and high $\mathrm{K}$ treatments; this further supports the allocation of $\mathrm{K}$ fertilizer treatments into the classes of $\mathrm{K}$-deficient and 
K-sufficient. Furthermore, logarithmic regression showed a strong negative relationship between plant $\mathrm{N}$ and plant $\mathrm{K}$ at the time of aphid infestation (113 DAS) $(\mathrm{F}=44.782$, df $\left.=1,11, \mathrm{P}<0.01, \mathrm{R}^{2}=0.818\right)$, indicating that plant $\mathrm{N}$ decreased as plant $\mathrm{K}$ increased (Fig. 3f).

\section{Classification of K-deficiency: multi-spectral imagery}

For each combination of spatial resolution (i.e. pixel size attained at imaging height) and date, K-deficiency was more accurately classified using $65 \mathrm{~mm}$ resolution than $8.1 \mathrm{~mm}$ resolution for both leaf pixels and all pixels (Table 1). The highest classification accuracy at resolution was achieved using leaf pixels at 113 DAS (93.9\%); highest classification accuracy at $65 \mathrm{~mm}$ resolution was $100 \%$ on 96 and 113 DAS using leaf pixels. Removing background pixels to classify reflectance from leaf pixels made no difference in classification accuracy for images acquired 69 DAS for 0.81 or $65 \mathrm{~mm}$ resolution, and the same or similar bands were selected regardless of background removal. However, classification accuracy increased when background pixels were removed for $8.1 \mathrm{~mm}$ resolution images at 96 DAS, 69+96 DAS, 113 DAS and 3 dates combined. Furthermore, the bands chosen for the model, in order of importance, changed markedly between the combinations of days, spatial resolution, and pixel selection (i.e. leaf or all).

The reflectance profiles of the multi-spectral imagery showed much stronger spectral groupings between leaf and background pixels in $8.1 \mathrm{~mm}$ resolution images compared to $65 \mathrm{~mm}$ resolution, indicating that radiometric filtering is more robust at higher spatial resolutions and more pixel dilution occurs at lower resolutions (Fig. 4).

It is apparent amongst reflectance profiles of leaf, background and all pixels that mean reflectance values of leaf pixels can be diluted substantially with background pixels (Fig. 4). For example, in high-resolution $(8.1 \mathrm{~mm})$ imagery at 113 DAS (Fig. 4e), there were marked differences in reflectance between K-deficient and K-sufficient plots, particularly in the near-infrared bands $(720,800$ and $900 \mathrm{~nm})$, when all pixels were included in mean reflectance assessments. However, the differences between K-deficient and $\mathrm{K}$-sufficient reflectance profiles were much less pronounced for leaf pixels. Furthermore, it is evident that the amount (\%) and nature (shadow, stubble, soil, flowers) of background in the images substantially altered the mean reflectance profile (Fig. $4 \mathrm{~g}$ ). For example, it was visually obvious that images acquired at 69 DAS contained mostly soil and stubble in the background, while images at 96 DAS contained much more shadow due to larger crop biomass. This further complicates temporal extrapolation of classified canopy reflectance data when background pixels are not excluded.

The reflectance values of leaf pixels were similar between the three imaging dates at $8.1 \mathrm{~mm}$ resolution, indicating that selection of leaf pixels via radiometric filter is robust at this resolution (Fig. 4a, c, e). However, very little difference in reflectance occurred between K-sufficient and K-deficient plants at $8.1 \mathrm{~mm}$ resolution except at 69 DAS for 550 and $900 \mathrm{~nm}$ bands which decreased in reflectance from K-sufficient to K-deficient 6 and $8 \%$ respectively. For leaf pixels at $65 \mathrm{~mm}$ resolution, decreases in reflectance between $\mathrm{K}$ sufficient and K-deficient (i.e. percent change was negative) were consistently seen at 69 , 96 and 113 DAS for near-infrared bands (720, 800 and $900 \mathrm{~nm})$, while differences in visible bands (490, 550 and $680 \mathrm{~nm}$ ) either increased or decreased in reflectance (Fig. 5b).

Amongst all combinations of spatial resolution and imaging dates, the greatest differences in relative reflectance between K-deficient and K-sufficient plants were at $65 \mathrm{~mm}$ resolution when all pixels were used, with band $5(800 \mathrm{~nm})$ showing the greatest differences of $-4.8,-8.4$ and $-9.2 \%$ for 69,96 and 113 DAS, respectively (Fig. 5a). Using all 


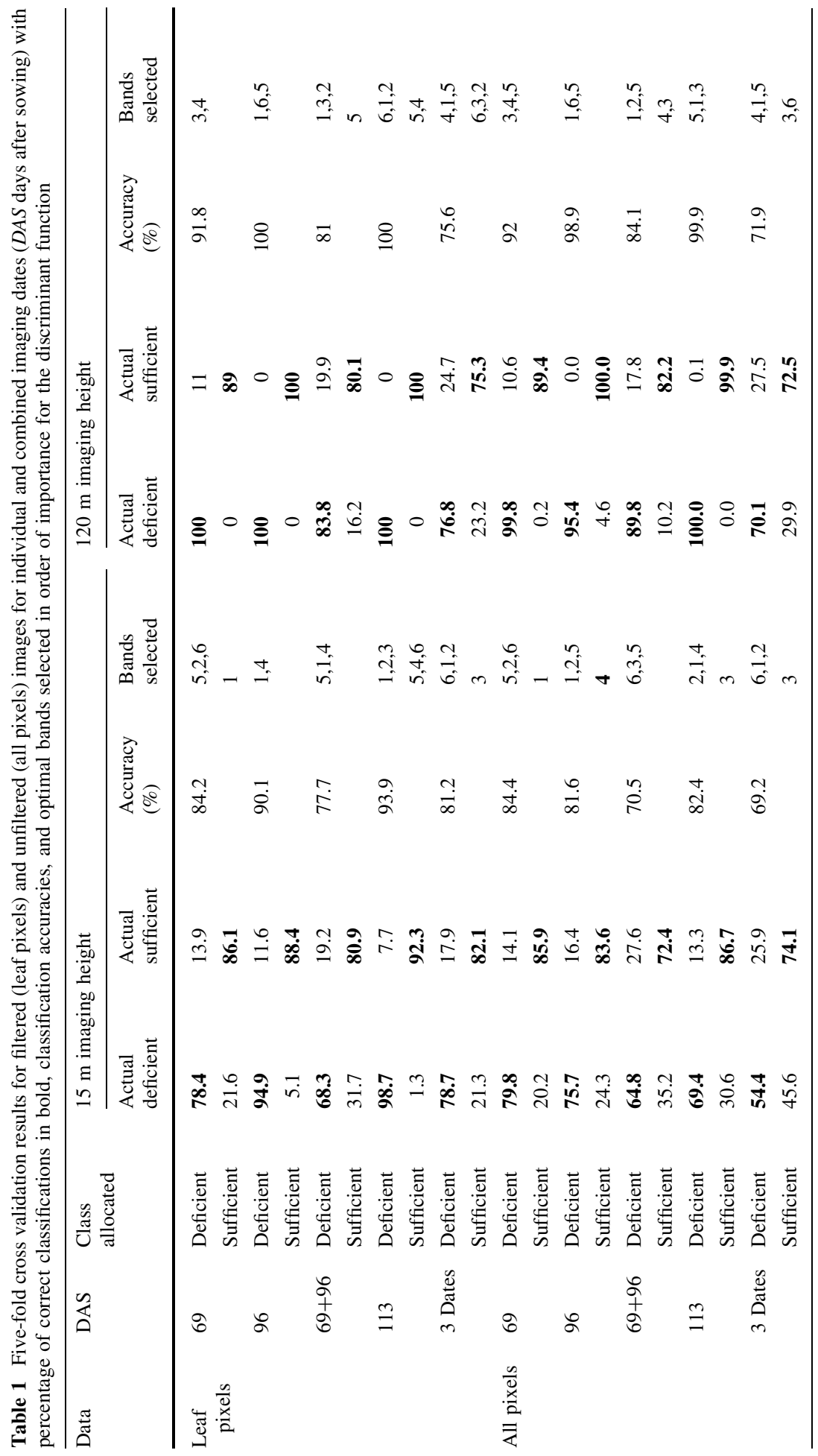




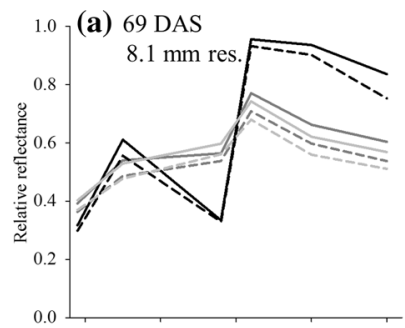

(b) $69 \mathrm{DAS}$

$65 \mathrm{~mm}$ res.

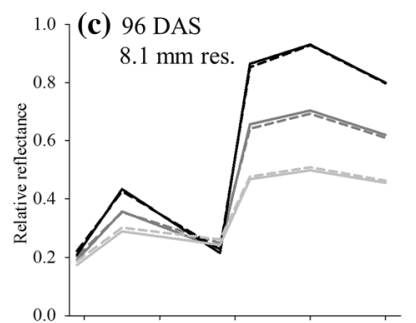

(d) $96 \mathrm{DAS}$

$65 \mathrm{~mm}$ res.

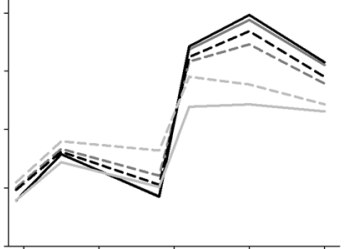

Deficient All ----
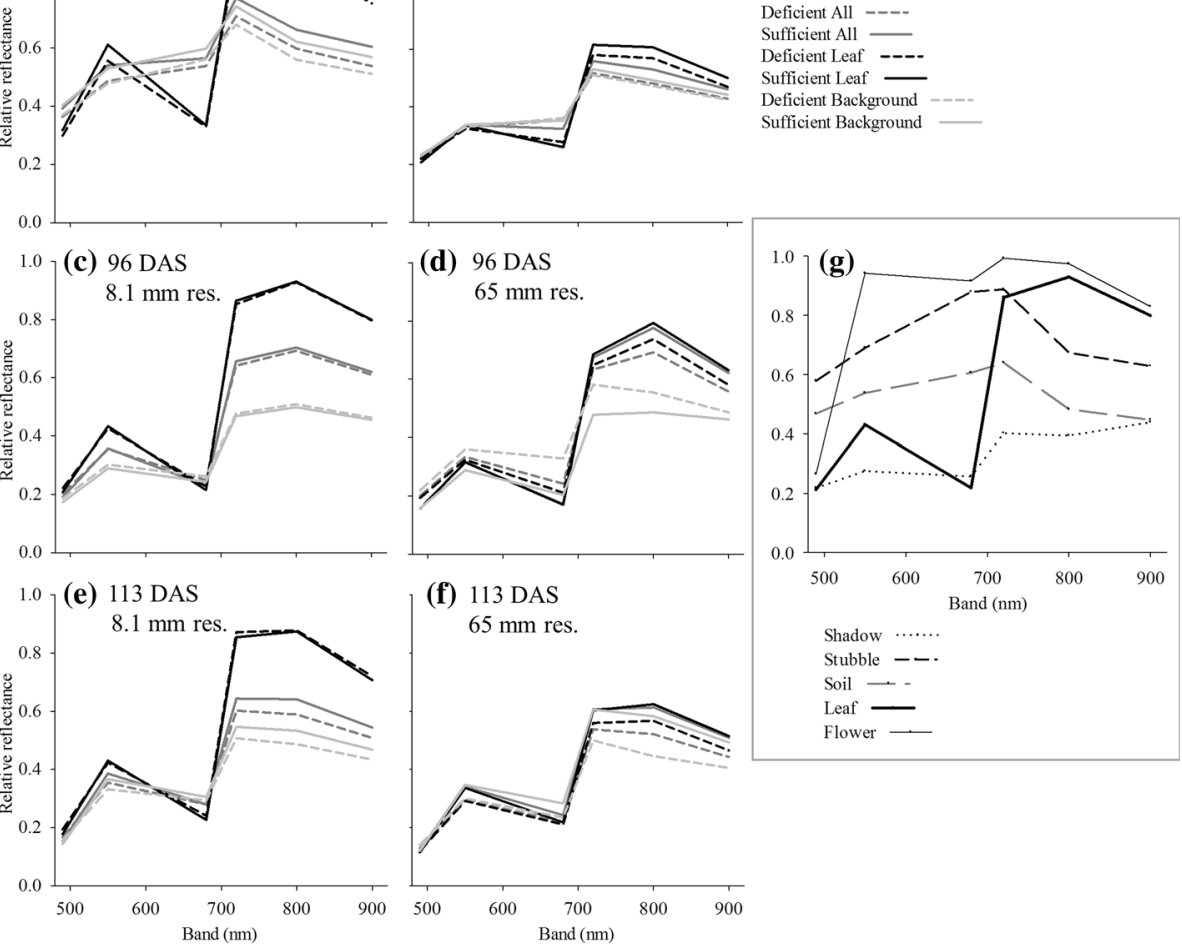

Fig. 4 Relative reflectance profiles of six MCA bands (490, 550, 680, 720, 800, and $900 \mathrm{~nm}$ ) for leaf, background, and all pixels within K-deficient and K-sufficient classes for each combination of imaging date $(69,96$, and 113 DAS) and spatial (pixel) resolution $(8.1$ and $65 \mathrm{~mm})$

(a) All pixels

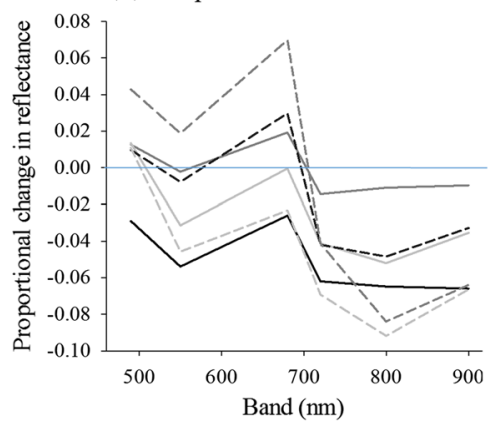

(b) Leaf pixels

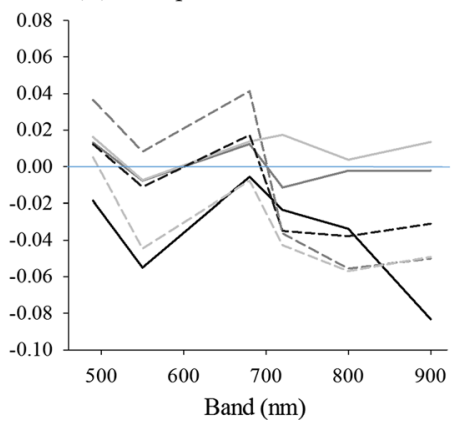

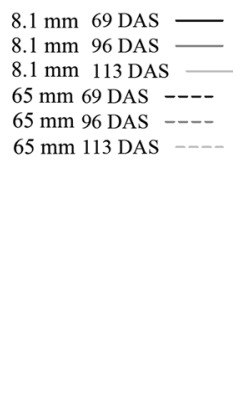

Fig. 5 Percent change in reflectance from K-sufficient to K-deficient for 69, 96, and 113 DAS at $8.1 \mathrm{~mm}$ (solid line; $15 \mathrm{~m} \mathrm{UAV}$ height) and $65 \mathrm{~mm}$ (dashed line; $120 \mathrm{~m}$ UAV height) spatial resolutions using all pixels (a) and leaf pixels only (b) 
pixels, band $3(680 \mathrm{~nm})$ showed 3.0, 7.0 and $-2.3 \%$ changes in reflectance at 69,96 and 113 DAS respectively. Although greater differences in reflectance were seen at $65 \mathrm{~mm}$ resolution when all pixels were used for all three dates, the same classification accuracy (92\%) was achieved at 69 DAS with and without background removal, and more accurate classification was achieved at 96 and 113 DAS with background removal (Table 1).

When LAI and NDVI values were plotted for each sub-plot region, groupings were more pronounced at $65 \mathrm{~mm}$ resolution (Fig. 6). It is apparent that, although increased LAI was strongly associated with increased NDVI for both image resolutions, K-deficient and $\mathrm{K}$-sufficient classes overlapped considerably within imaging dates, with no clear separation, at $8.1 \mathrm{~mm}$ resolution. However, much more separation between image date and $\mathrm{K}$ groups was evident at $65 \mathrm{~mm}$ resolution. For 96 DAS, clear separation of K-deficient and K-sufficient sub-plots occurred at 0.55 NDVI while LAI values overlapped. For $65 \mathrm{~mm}$ resolution at 69 DAS, NDVI values overlapped, and most separation of LAI values occurred at approximately 0.18 (i.e. $18 \%$ vegetation cover). This indicates that LAI was a more robust predictor of K-deficient plots at seedling stages, while NDVI was more robust at more advanced growth stages (i.e. more biomass and less background).

\section{Classification of K-deficiency: hyperspectral imagery}

Using hyperspectral images of individual canola plants, the highest classification accuracy was $87.9 \%$ on 69 DAS which decreased to $82.5 \%$ at 96 DAS. Classification accuracy further diminished to $78.4 \%$ when 69 and 96 DAS data was combined (Table 2). Using reflectance values of MCA-equivalent bands extracted from the hyperspectral reflectance data further diminished classification accuracy below $76 \%$ for all combinations of days.

The reflectance profiles from hyperspectral images of canola plants differed more between days than between the $\mathrm{K}$ classes themselves (Fig. 7). The highest difference in reflectance occurred at approximately $540 \mathrm{~nm}$ for 69 DAS $(1.6 \%)$ and $490 \mathrm{~nm}(-1.1 \%)$ for 96 DAS (Fig. 7b). The change in relative reflectance from K-sufficient to K-deficient follows very similar curves from approx. 490 to $720 \mathrm{~nm}$. Furthermore, the main peaks and dips in the curves correspond closely to the MCA band values at 490, 550, 680 and 720.

(a) $8.1 \mathrm{~mm}$ res.

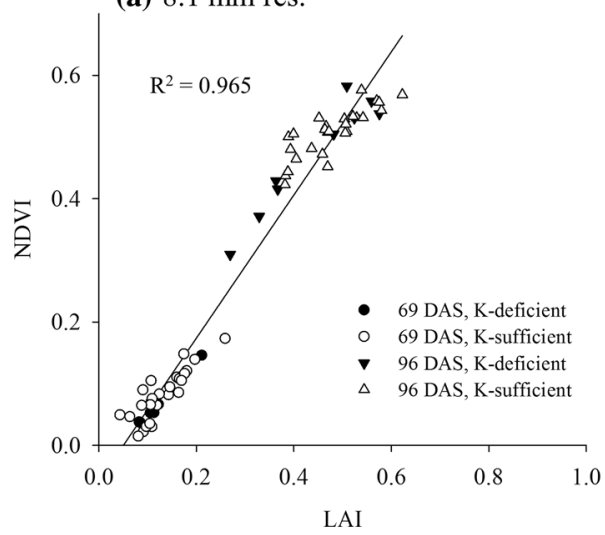

(b) $65 \mathrm{~mm}$ res.

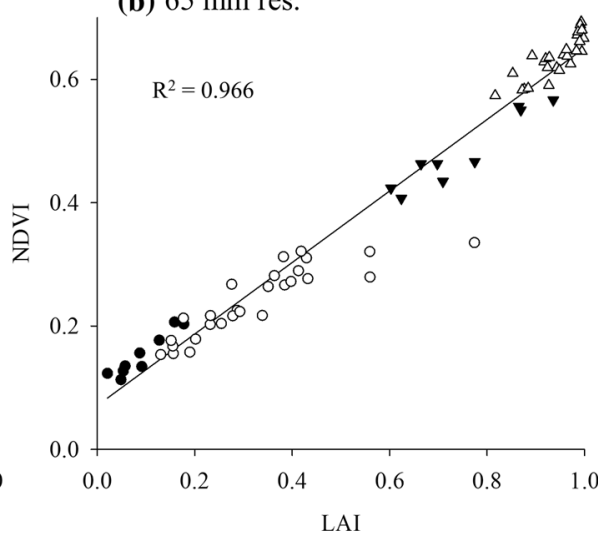

Fig. 6 Average LAI against NDVI for each sub-plot with symbols indicating K-deficient and K-sufficient classes at 69 and 96 DAS for $8.1 \mathrm{~mm}$ (a) (15 m UAV height) and $65 \mathrm{~mm}$ (b) (120 m UAV height) spatial resolutions 


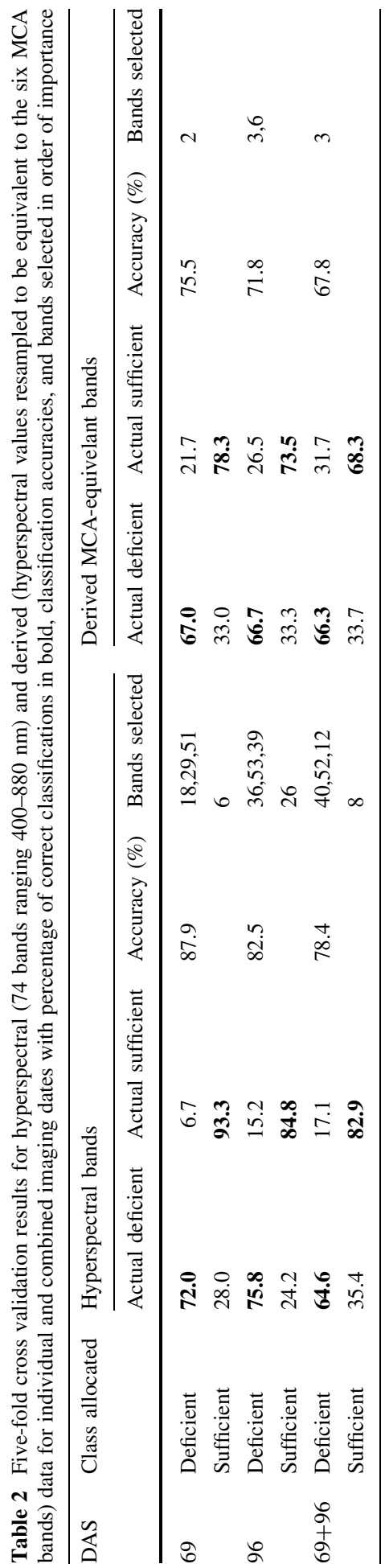



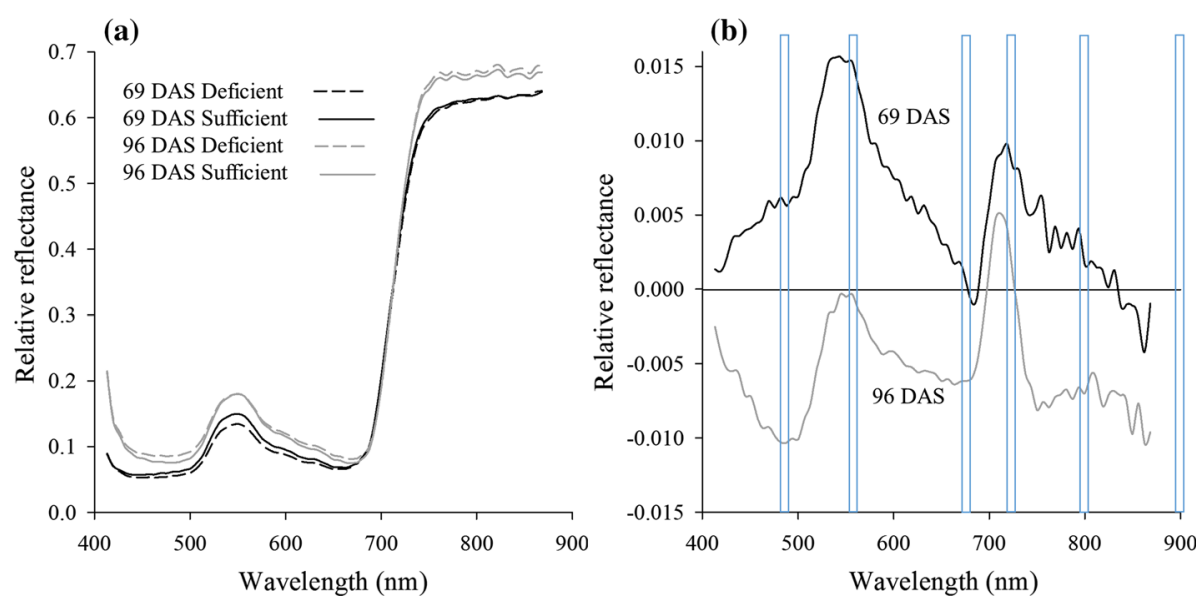

Fig. 7 Average relative reflectance profiles of hyperspectral imagery of individual plants from K-deficient and K-sufficient plots at 69 and 96 DAS (a); average change in relative reflectance from K-sufficient to K-deficient for 69 and 96 DAS images (b) with vertical bars representing the six MCA bands

However, overall classification accuracies were less than that achieved via field-based multi-spectral imagery.

\section{Green peach aphid performance}

Of 600 individual plants assessed across plots, counts of GPA per plant ranged from 0 to 210, and only eight plants contained no GPA (i.e. $99 \%$ infestation). All GPA were found on the underside of leaves; none were found on racemes. On average, significantly higher numbers of GPA were counted on K-deficient plants (i.e. low K) than on K-sufficient plants (i.e. residual, medium and high $\mathrm{K})(\mathrm{F}=34.57$, $\mathrm{df}=3,594, \mathrm{P}<0.01)$. Average GPA per plant was $37.8 \pm 2.7 \mathrm{SE}$ (standard error of mean), $27.5 \pm 2.4,25.6 \pm 2.0$, and $19.8 \pm 1.3 \mathrm{SE}$ for low, residual, medium and high $\mathrm{K}$ treatments respectively (least significant difference of means $=5.67$ ). For K-sufficient and K-deficient classes, this equates to averages of $24.3 \pm 1.9$ and $37.8 \pm 2.7 \mathrm{SE}$ respectively; an overall increase in GPA populations of $56 \%$.

\section{Discussion}

\section{Classification of K-deficient canola according to canopy reflectance data}

In this study, it was demonstrated that K-deficient canola plants could be differentiated from K-sufficient plants, using canopy reflectance data, and that this was best achieved using lower resolutions. The field experiment showed that 50,100 and $400 \mathrm{~kg} \mathrm{ha}^{-1}$ (residual from 2012 application) MOP fertilizer regimes all provided sufficient amounts of $\mathrm{K}$ for canola production, and that plots with no added $\mathrm{K}$ fertilizer resulted in deficient concentrations of $\mathrm{K}$ in plant tissue.

In canola, the concentrations of $\mathrm{K}$ in leaf tissue (i.e. youngest mature leaf) required for maximum yield is $2.8-5 \%$ (Brennan and Bolland 2007). It is not surprising then that the 
low K treatment ("K-deficient"), consisting of plant K concentrations below $2 \%$ resulted in significantly lower seed yield. Furthermore, this explains why the medium $\mathrm{K}$, residual $\mathrm{K}$ and high $\mathrm{K}$ treatments (all termed "sufficient $\mathrm{K}$ " in the presented results) showed very little differences in plant tissue K (Fig. 3b), and no differences in yield, when there were different absolute levels of soil K, albeit sufficient (Fig. 3a).

With regards to nutrient deficiencies, canopy reflectance data has mostly been applied to classification of nitrogen (Muñoz-Huerta et al. 2013; Mahajan et al. 2014). However, it has been shown that changes in canopy reflectance typical of $\mathrm{N}$ status become less indicative when $\mathrm{K}$ is not sufficient, and this complicates sensor-driven variable rate applications of $\mathrm{N}$ (Fridgen and Varco 2004). A potential explanation of why the $65 \mathrm{~mm}$ resolution canopy reflectance data achieved higher classification accuracy than the $8.1 \mathrm{~mm}$ resolution data could be that lower resolution integrated more the effects of reduced LAI in K-deficient plots compared to K-sufficient plots, even when background was filtered out. It could also be due to more error in band-to-band registration and ortho-rectification (i.e. removing the effects of image perspective or tilt) at $8.1 \mathrm{~mm}$ resolution which is more likely as the camera moves closer to the subject. The negative effects of these image processing steps were minimized by applying a radiometric filter which would exclude mis-aligned pixels. For example, it is evident in Fig. 1b that many green leaf pixels either at leaf edges or representing very small seedlings were excluded in the filtering process. Applying a radiometric filter to remove as much background as possible increased the classification accuracy for $65 \mathrm{~mm}$ resolution images, and this most likely occurred as a result of decreasing the influence of background pixels on the reflectance recorded at each band.

Greater imaging heights are beneficial by covering more area per image hence reducing time, labor and image pre-processing and processing requirements. However, higher image resolutions are required where reflectance of leaf pixels in the absence of background is important. As discussed, this high image resolution is a major advantage of UAV-acquired imaging as opposed to lesser resolution satellite imagery. Furthermore, multiple lenses such as in the MCA complicate band-to-band registration when processing the images, especially when multiple or unknown heights are used. Also, more bands may have increased the classification accuracy of K-deficient canola. It would therefore be a major improvement if a higher resolution, single-lens hyperspectral camera, which is lightweight enough to be UAV-mounted, be used to simplify image processing workflows and increase the spatial accuracy of plant canopy reflectance data.

\section{Effects of K-deficiency on $\mathrm{N}$-accumulation and green peach aphid performance}

This field study also found that K-deficient canola plots contained significantly more GPA than K-sufficient canola plants. K-deficiency resulted in increased concentrations of $\mathrm{N}$ (in the youngest mature leaves) and GPA and decreased LAI, NDVI and canola seed yield. Although the effects of GPA and K-deficiency on canola seed yield could not be differentiated at 113 DAS due to all plots being infested, it is clear that K-deficiency was the dominant yield-limiting factor.

With regards to the effects of K-deficiency on nitrogen accumulation in plant tissue, it is clear that $\mathrm{K}$-sufficient plants assimilated $\mathrm{N}$ into plant tissue given optimal levels of $\mathrm{K}$. However, deficient levels of $\mathrm{K}$ caused uptake and assimilation of $\mathrm{N}$ to be limited. This increase in $\mathrm{N}$ as a result of nutritional deficiency has been shown to increase the survival and abundance of arthropods, including aphids, as well as plant diseases (Emden et al. 1969; Eldridge et al. 1981). Further to accumulation of $\mathrm{N}$ in plant tissue, K-deficiency also 
caused decreased LAI and NDVI indicating that vegetation cover was less and therefore canola plants were stunted in their growth relative to K-sufficient plants. Increased performance of GPA on canola likely resulted from a combination of these factors.

This study supports much research on increased arthropod performance as a result of soil nutrient deficiency and further highlights the importance of ensuring sufficient amounts of $\mathrm{K}$ in soils, thereby reducing susceptibility to GPA as well as improving crop uniformity and yields. Importantly, $\mathrm{K}$ applied as a management strategy to reduce plant susceptibility to pests and diseases should be employed in a form which does not include $\mathrm{N}$ because increased $\mathrm{N}$, above sufficient amounts, may increase pest and disease performance.

\section{Conclusions}

This study, which was conducted over one growing season, demonstrated that field regions containing K-deficient canola plants were accurately classified relative to K-sufficient plants using canopy reflectance data acquired from a six-band MCA. Highest classification accuracies were achieved at $65 \mathrm{~mm}$ resolution with very similar results whether background pixels were removed or not. However, classification accuracies increased substantially when background pixels were removed for $8.1 \mathrm{~mm}$ resolution images acquired later in the growing season (96 and 113 DAS). Significant decreases in classification accuracy when imaging dates were combined implies that spatial assessments for heterogeneity of K-deficiency are best achieved on individual imaging dates and temporal extrapolation is relatively inaccurate. Furthermore, GPA were counted in much higher numbers on canola plants deficient in $\mathrm{K}$ than those with sufficient amounts of $\mathrm{K}$ in the soil and plant tissue. Although the effects of GPA and K-deficiency on yield and canopy reflectance 113 DAS could not be differentiated in combination, the study clearly demonstrated the importance of ensuring optimal amounts of $\mathrm{K}$ are applied to portions of a field which require it, thereby reducing susceptibility to GPA (and possibly other pests) as well as improving crop uniformity and yields. Similarity in plant stress response, as indicated by differences in canopy reflectance data, complicates detection of a specific disorder (e.g. K-deficiency), especially where more than one disorder is present. However, it is anticipated that mapped field regions displaying significant reductions in LAI and NDVI may be targeted for on-ground inspection for nutrient deficiency and early detection of pests and diseases. The discussed effect of background pixels on overall analyses of canopy reflectance data may be very influential albeit misleading where specific differences in leaf reflectance exist, which can only be accurately assessed using higher resolution imagery (i.e. higher resolution camera or lower UAV height).

Acknowledgments Appreciation is extended to Lloyd Groves and Genping Zhao for field technical support. Thanks also to CSBP for access to and maintenance of the trial site and analysis of soil and plant tissue samples. This research was funded by the Grains Research and Development Corporation and the Department of Agriculture and Food Western Australia.

Open Access This article is distributed under the terms of the Creative Commons Attribution 4.0 International License (http://creativecommons.org/licenses/by/4.0/), which permits unrestricted use, distribution, and reproduction in any medium, provided you give appropriate credit to the original author(s) and the source, provide a link to the Creative Commons license, and indicate if changes were made. 


\section{References}

Brennan, R. F., \& Bolland, M. D. A. (2006). Soil and tissue tests to predict the potassium requirements of canola in south-western Australia. Australian Journal of Experimental Agriculture, 46(5), 675-679.

Brennan, R. F., \& Bolland, M. D. A. (2007). Comparing the potassium requirements of canola and wheat. Australian Journal of Agricultural Research, 58(4), 359-366.

Brennan, R. F., Bolland, M. D. A., \& Ramm, R. D. (2013). Changes in chemical properties of sandy duplex soils in 11 paddocks over 21 years in the low rainfall cropping zone of southwestern Australia. Communications in Soil Science and Plant Analysis, 44(12), 1885-1908.

Chen, L., Lin, L., Cai, G., Sun, Y., Huang, T., Wang, K., et al. (2014). Identification of nitrogen, phosphorus, and potassium deficiencies in rice based on static scanning technology and hierarchical identification method. PLoS ONE, 9(11), e113200.

Colomina, I., \& Molina, P. (2014). Unmanned aerial systems for photogrammetry and remote sensing: A review. ISPRS Journal of Photogrammetry and Remote Sensing, 92, 79-97.

Cook, S. E., \& Bramley, R. G. V. (2000). Coping with variability in agricultural production-implications for soil testing and fertiliser management. Communications in Soil Science and Plant Analysis, 31(11-14), 1531-1551.

Defernez, M., \& Kemsley, E. K. (1997). The use and misuse of chemometrics for treating classification problems. TrAC Trends in Analytical Chemistry, 16(4), 216-221.

Edwards, J., \& Hertel, K. (2011). Canola growth and development. In J. Edwards (Ed.), Procrop. New South Wales: Department of Primary Industries.

Eldridge, R. H., Turner, J., \& Lambert, M. J. (1981). Dothistroma needle blight in a New South Wales Pinus radiata plantation in relation to soil types. Australian Forestry, 44(1), 42-45.

Emden, H. F. V., Eastop, V. F., Hughes, R. D., \& Way, M. J. (1969). The ecology of Myzus persicae. Annual Review of Entomology, 14(1), 197-270.

ESRI (2014). ArcMap. (10.2.2 ed.). Redlands, California, USA.: Environmental Systems Resource Institute.

Fridgen, J. L., \& Varco, J. J. (2004). Dependency of cotton leaf nitrogen, chlorophyll, and reflectance on nitrogen and potassium availability. Agronomy Journal, 96(1), 63-69.

Ge, Y., Thomasson, J. A., \& Sui, R. (2011). Remote sensing of soil properties in precision agriculture: A review. Frontiers of Earth Science, 5(3), 229-238.

Jones, H. G., \& Vaughan, R. A. (2010). Integrated applications. In H. G. Jones \& R. A. Vaughan (Eds.), Remote sensing of vegetation: Principles, techniques, and applications (pp. 271-331). Oxford: Oxford University Press.

Kelcey, J., \& Lucieer, A. (2012). Sensor correction of a 6-band multispectral imaging sensor for UAV remote sensing. Remote Sensing, 4(5), 1462-1493.

Lee, W. S., Alchanatis, V., Yang, C., Hirafuji, M., Moshou, D., \& Li, C. (2010). Sensing technologies for precision specialty crop production. Computers and Electronics in Agriculture, 74(1), 2-33.

Loss, S. (2012). CSBP soil \& plant analysis method summaries. Western Australia: Kwinana.

Mahajan, G. R., Sahoo, R. N., Pandey, R. N., Gupta, V. K., \& Kumar, D. (2014). Using hyperspectral remote sensing techniques to monitor nitrogen, phosphorus, sulphur and potassium in wheat (Triticum aestivum L.). Precision Agriculture, 15(5), 499-522.

Muñoz-Huerta, R., Guevara-Gonzalez, R., Contreras-Medina, L., Torres-Pacheco, I., Prado-Olivarez, J., \& Ocampo-Velazquez, R. (2013). A review of methods for sensing the nitrogen status in plants: Advantages, disadvantages and recent advances. Sensors, 13(8), 10823-10843.

Nansen, C., Geremias, L. D., Xue, Y., Huang, F., \& Parra, J. R. (2013a). Agricultural case studies of classification accuracy, spectral resolution, and model over-fitting. Applied Spectroscopy, 67(11), 1332-1338.

Nansen, C., Sidumo, A. J., \& Capareda, S. (2010). Variogram analysis of hyperspectral data to characterize the impact of biotic and abiotic stress of maize plants and to estimate biofuel potential. Applied Spectroscopy, 64(6), 627-636.

Nansen, C., Sidumo, A. J., Martini, X., Stefanova, K., \& Roberts, J. D. (2013b). Reflectance-based assessment of spider mite "bio-response" to maize leaves and plant potassium content in different irrigation regimes. Computers and Electronics in Agriculture, 97, 21-26.

Pettorelli, N. (2013). The normalized difference vegetation index. Oxford: Oxford University Press.

Pimstein, A., Karnieli, A., Bansal, S. K., \& Bonfil, D. J. (2011). Exploring remotely sensed technologies for monitoring wheat potassium and phosphorus using field spectroscopy. Field Crops Research, 121(1), $125-135$.

Prabhakar, M., Prasad, Y. G., \& Rao, M. (2012). Remote sensing of biotic stress in crop plants and its applications for pest management. In B. Venkateswarlu, A. K. Shanker, C. Shanker, \& M. Maheswari 
(Eds.), Crop stress and its management: Perspectives and strategies (pp. 517-545). Dordrecht: Springer.

Rayment, G. E., \& Lyons, D. J. (2011). Soil Chemical Methods-Australasia. Collingwood: CSIRO Publishing.

Rouse, J. W., Haas, R. H., Schell, J. A., \& Deering, D. W. (1974). Monitoring vegetation systems in the Great Plains with ERTS. In NASA Goddard Space Flight Center 3d ERTS-1 Symposium, United States (pp. 309-317).

Wang, M., Zheng, Q., Shen, Q., \& Guo, S. (2013). The critical role of potassium in plant stress response. International Journal of Molecular Sciences, 14(4), 7370-7390.

Watts, A. C., Ambrosia, V. G., \& Hinkley, E. A. (2012). Unmanned aircraft systems in remote sensing and scientific research: Classification and considerations of use. Remote Sensing, 4(6), 1671-1692.

West, K., \& Nansen, C. (2014). Smart-use of fertilizers to manage spider mites (Acari: Tetrachynidae) and other arthropod pests. Plant Science Today, 1(3), 161-164.

Whelan, B., \& Taylor, J. (2013). Precision agriculture for grain production systems. Collingwood: CSIRO Publishing.

Zhang, C., \& Kovacs, J. (2012). The application of small unmanned aerial systems for precision agriculture: a review. Precision Agriculture, 13(6), 693-712.

Zörb, C., Senbayram, M., \& Peiter, E. (2014). Potassium in agriculture-Status and perspectives. Journal of Plant Physiology, 171(9), 656-669. 